FORMAÇÃO DE PROFISSIONAIS DA EDUCAÇÃO

\title{
ALGUNS DESAFIOS E DEMANDAS DA FORMAÇÃO INICIAL DE PROFESSORES NA CONTEMPORANEIDADE
}

\author{
Eliana Alves Pereira Leite ${ }^{1}$ \\ Emerson da Silva Ribeiro ${ }^{1}$ \\ Kécio Gonçalves Leite ${ }^{2}$ \\ Marcia Rosa Uliana ${ }^{1}$
}

\begin{abstract}
RESUMO: Este artigo abordou alguns desafios e demandas contemporâneos da formação inicial de professores no Brasil, com foco em aspectos das atuais Diretrizes Curriculares Nacionais de formaçáo de professores (Resolução no 2/CNE/2015), que requerem adequaçôes nos currículos dos cursos de licenciatura. As consideraçóes e reflexóes analíticas foram desenvolvidas por ocasião da recente reformulação de projetos pedagógicos de cursos de licenciatura na Universidade Federal de Rondônia (UNIR) e estão fundamentadas em autores dos campos da formaçáo de professores e correlatos. São abordados aspectos recorrentes em pesquisas sobre formação inicial de professores, evidenciando-se que, embora existam marcos legais que têm demandado atualizaçóes dos cursos de licenciatura, ainda náo se tem garantias de superaçáo de certos desafios a partir, apenas, da atualização de currículos. Em função de atuais transformaçóes sociopolíticas em andamento no país, novas demandas e desafios devem ser considerados na formaçáo inicial, devendo haver uma consonância entre a previsão normativa dos regulamentos legais e a prática existente em cursos de licenciatura.
\end{abstract}

Palavras-chave: Formação inicial de professores. Diretrizes Curriculares Nacionais para formação docente. Profissão docente. Desafios e demandas contextualizadas à profissão docente.

\section{SOME CHALLENGES AND DEMANDS OF INITIAL TEACHER TRAINING IN CONTEMPORARY TIMES}

ABSTRACT: This article discusses some of the contemporary challenges
and demands of initial teacher education in Brazil, focusing on aspects of the
current National Curriculum Guidelines for teacher education (Resolution
2/2015 of the National Conference on Education, NCE), which require
adjustments in curricula for undergraduate courses. Considerations and
analytical reflections were developed in conjunction with the recent

\footnotetext{
${ }^{1}$ Universidade Federal de Rondônia, Departamento de Matemática e Estatística - Ji-Paraná (RO), Brasil.

E-mails: eliana.leite@unir.br; emerson@unir.br; marcia.uliana@unir.br

${ }^{2}$ Universidade Federal de Rondônia, Departamento de Educação Intercultural - Ji-Paraná (RO), Brasil.

E-mail: kecioleite@unir.br

DOI: 10.1590/ES0101-73302018183273
} 
process of reformulating undergraduate courses' pedagogical projects at the Universidade Federal de Rondônia, and are based on authors in teacher training and other related fields. We discuss recurrent aspects in research on initial teacher education, demonstrating that, although there are legal frameworks, which have required that undergraduate courses be updated, there is still no guarantee that certain challenges will be overcome just from updating the curriculum. Due to current sociopolitical transformations in progress in the country, new demands and challenges must be considered in initial training. Furthermore, there should be an agreement between the normative forecast of legal regulations and existing practices in undergraduate courses.

Keywords: Initial teacher training. National Curricular Guidelines for teacher training. Teaching profession. Challenges and demands contextualized to the teaching profession.

\section{QUELQUES DÉFIS ET EXIGENCES DE LA FORMATION INITIALE DES ENSEIGNANTS À L'ÉPOQUE CONTEMPORAINE}

Résumé: Cet article aborde des certaines exigences et défis contemporains rencontrés dans la formation initiale des enseignants au Brésil, en se concentrant sur les aspects des Directrices Nationales du Curriculum pour la formation des enseignants (Rèsolution 2/2015 à la Conférence Nationale pour l'Éducation, CNE), qui ont besoin des ajustements dans les programmes des cours de licence. Les considérations et réflexions analytiques ont été développées lors de la reformulation récente de projets pédagogiques de ces cours à l'Universidade Federal de Rondônia, et sont basées sur des auteurs des domaines de la formation des enseignants et autres disciplines similaires. On discute les aspects récurrents dans la recherche sur la formation initiale des enseignants, en montrant que, bien qu'il existe des réglementations légales qui ont exigé la mise à jour des cours de formation initiale, Il n'est pas assuré que les défis qui se posent soient dépassés. En raison des transformations sociopolitiques en cours dans le pays, de nouvelles demandes et de nouveaux défis doivent être pris en compte dans la formation initiale, et il doit y avoir une convergence entre la prévision normative des réglementations légales et la pratique actuelle dans les cours de formation initiale.

Mots-clés: Formation initiale des enseignants. Directrices Nationales du Curriculum pour la formation des enseignants. Profession d'enseignement. Défis et demandes contextualisés à la profession d'enseignement.

\section{Introdução}

a contemporaneidade, dentre vários desafios da formação docente, destaca-se o de formar profissionais que atendam a uma multiplicidade de demandas emergentes no contexto educacional, especialmente 
no que diz respeito à escola enquanto lócus de atuação. Especificamente no Brasil, novas atualizações em cursos de formação inicial de professores estão sendo requeridas por força de regulamentos e marcos legais que resultaram de debates e estudos acumulados nas últimas décadas.

Atualmente, os cursos de licenciatura de todo o país estáo se ajustando às Diretrizes Curriculares Nacionais $(\mathrm{DCN})$ estabelecidas pela Resolução ${ }^{\circ}$ 2, de $1^{\circ}$ de julho de 2015, do Conselho Nacional de Educaçáo (CNE), cujo ciclo de plena implementação se esgota, em prazo já prorrogado, em julho de 2018 (BRASIL, 2015b). Nesse contexto, impóe-se às instituiçóes formadoras, a partir dos núcleos docentes estruturantes dos cursos de licenciatura, a necessidade de se repensar a formaçáo inicial de professores, agora orientada por novos marcos e critérios. Ao mesmo tempo, desafios e problemáticas recorrentes em pesquisas sobre a formação docente no país ainda não foram superados, exigindo-se, para tanto, novas configuraçóes de cursos e a implantação de novas práticas de formação inicial, para além das previsões normativas e regulamentares, que se relacionem efetivamente com as transformaçóes sociopolíticas em andamento, cujos reflexos se fazem sentir na escola e na reorganização de toda a educação básica.

Foi a partir dessa realidade concreta e dessa vivência atual que se deu a produção deste artigo, no sentido de compartilharmos algumas impressões e reflexóes analíticas que nos ocorreram quanto a alguns desafios e demandas atuais da formação de professores em nosso país, com base em estudos que realizamos ao participarmos da recente reconstrução de projetos pedagógicos de cursos de licenciatura na Universidade Federal de Rondônia (UNIR).

Além dos atuais desafios e demandas, a formação docente é, reconhecidamente, uma ação complexa, sobretudo quando se reflete a respeito do papel do professor, bem como sobre sua função social. Para Serrazina (2012, p. 267), "ser professor sempre foi uma profissão complexa. Esta complexidade tem tendência a acentuar-se com a incerteza e imprevisibilidade que caracteriza este início do século XXI". Por sua vez, Imbernón (2009, p. 8) apresenta elementos que contribuem para a compreensão do que seriam essas incertezas, que dizem respeito ao fato de que "os contextos sociais e educativos que condicionam todo o ato social, e, portanto, a formação, mudaram muito".

É sabido que sempre houve mudanças na sociedade que demandaram reorientações na formação de professores e que novas mudanças continuarão ocorrendo. Contudo, para Imbernón (2009, p. 8), as transformações dos últimos decênios foram especialmente bruscas e "deixaram muitos na ignorância, no desconcerto e, por que não dizer, numa nova pobreza (material e intelectual) devido à comparação possibilitada pela globalização de fatos e fenômenos".

Dentre outros aspectos, isso traz à tona a fluidez, a volatilidade e a superficialidade de informaçôes e conhecimentos que têm perpassado o cotidiano 
das pessoas de uma forma geral e, nesse movimento, o professor tem que aprender a se reinventar e a lidar com as novas demandas, muitas vezes ainda desconhecidas e, portanto, desafiadoras. Além do mais, esse processo acrescenta ao docente o enfrentamento de um cenário de desprestígio social para com sua profissão e a desvalorização profissional em várias dimensões. Nesse contexto, é imprescindível não deixar de se considerar a relevância social desse profissional e, portanto, valorizá-lo, visto que:

É um profissional do humano que ajuda o desenvolvimento pessoal e intersubjetivo do aluno, sendo um facilitador de seu acesso ao conhecimento; é um ser de cultura que domina sua área de especialidade científica e pedagógica-educacional e seus aportes para compreender o mundo; um analista crítico da sociedade, que nela intervém com sua atividade profissional; um membro de uma comunidade científica, que produz conhecimento sobre sua área e sobre a sociedade (PIMENTA; LIMA, 2012, p. 88).

Ao se reconhecer alguns aspectos que dizem respeito ao papel do professor, bem como a sua função social, também se evidencia a necessidade do profissional docente possuir uma variedade de conhecimentos, saberes e habilidades de diferentes naturezas para assumir a tarefa educativa diante da abrangência e complexidade da educação, não se limitando a, mas perpassando o domínio dos conhecimentos pedagógicos e dos conteúdos específicos da área de atuação e formação. Tais conhecimentos, saberes e habilidades têm se traduzido em demandas próprias do exercício da profissão docente, refletidas em discussóes relacionadas à sólida formação científica e cultural do ensinar e aprender, apontando-se para a necessidade de aprendizagem de práticas educativas baseadas na interdisciplinaridade e transdisciplinaridade, na contextualização curricular e no uso das tecnologias e metodologias diferenciadas de ensino.

Tais demandas também têm se traduzido em desafios da contemporaneidade, associados à formação requerida para atuar nas diferentes etapas e modalidades da educação básica; no atendimento às características singulares de crianças, adolescentes, jovens e adultos; no desenvolvimento de açóes inclusivas e emancipadoras dos alunos e no reconhecimento e valorização da diversidade.

Todos esses aspectos trazem à tona a reflexão de que "ensinar sempre foi difícil, mas nos dias de hoje passou a ser ainda mais difícil" (IMBERNÓN, 2009, p. 90), que tem repercussão direta sobre os cursos de formação inicial de professores, exigindo que esses sejam repensados e reelaborados constantemente, na tentativa de se atender às demandas emergentes (MIZUKAMI, 2008; IMBERNÓN, 2009).

Diante disso, neste artigo, teceram-se consideraçóes analíticas e reflexóes teóricas sobre alguns dos desafios e demandas que têm se apresentado na contemporaneidade à formação docente, a partir de marcos legais que regulamentam a forma- 
ção inicial de professores em cursos de licenciatura, focando principalmente alguns aspectos decorrentes da implementação das atuais DCN, estabelecidas pela Resoluçâo no 2/CNE/2015 (BRASIL, 2015b). Dada a amplitude do tema, buscou-se delimitar a análise a alguns aspectos dessas atuais DCN que se sobressaem no processo de atualização pelo qual passam, hoje, os cursos de licenciatura no país.

\section{Formação inicial de professores}

A formação de professores para atuarem em diferentes níveis de ensino da educação básica é permeada por questôes recorrentes em debates e pesquisas no Brasil, sendo que, embora haja um aparato legal que normatize o assunto, mudanças significativas no processo geralmente não se constituem como efetivas, em decorrência de fatores como alta rotatividade e descontinuidade de políticas públicas de formaçáo de professores; descompasso entre o perfil de formadores e aquele esperado para os egressos dos cursos de licenciatura e ausência de políticas de acompanhamento e de avaliaçáo de currículos das licenciaturas e, também, por questóes recentes que se apresentam em função das novas demandas da contemporaneidade. Para Mizukami (2008, p. 215), dentre outros aspectos, os questionamentos postos e os que surgem são levantados tanto pela "necessidade de se formar bons professores para cada sala de aula de cada escola, quanto pelo desafio de oferecer processos formativos pertinentes a um mundo em mudanças".

Para se tecer consideraçóes e reflexôes sobre alguns dos desafios e demandas da formação inicial de professores no Brasil, é importante que se tenha uma compreensão acerca do papel desse contexto formativo mediante a legislação vigente e aos autores que abordam a formação de professores.

A Resolução no 02/CNE/2015, em seu Art. 10, define que "a formação inicial se destina àqueles que pretendem exercer o magistério da educação básica em suas etapas e modalidades de educação" (BRASIL, 2015b). E, conforme preconizado no Art. $9^{\circ}$, são considerados, com relação ao nível superior de formação inicial para os profissionais do magistério para a educação básica, os "cursos de graduaçáo de licenciatura; cursos de formaçáo pedagógica para graduados náo licenciados; e cursos de segunda licenciatura" (BRASIL, 2015b).

Nessas diretrizes são abordados aspectos que elucidam a base comum curricular de formaçáo, que deve ser contemplada pelas diferentes instituiçóes de ensino superior (IES) que ofertam cursos de licenciatura, perpassando pelos conhecimentos, saberes e habilidades que os egressos dos cursos de graduação deverão possuir e, portanto, o repertório desses elementos educacionais que deverá ser construído na formação inicial do futuro professor.

Ressalta-se que, ao se definir por diretrizes a base curricular comum aos cursos de licenciatura, não se está, com isso, restringindo a formação de professo- 
res apenas ao curso de graduaçáo. Nesse sentido, conforme apontado na literatura sobre o tema, tem-se um entendimento de que a formaçáo docente, dada a sua complexidade, não se limita a uma instituição, contexto ou período temporal, ocorrendo, segundo Lima e Reali (2010, p. 219), "em vários contextos e instituiçóes e ao longo de toda a experiência escolar e não escolar dos futuros professores". Isso está respaldado na compreensão de que a aprendizagem profissional da docência se constitui em "um processo complexo, contínuo, marcado por oscilaçóes e descontinuidades e não por uma série de acontecimentos lineares" (LIMA; REALI, 2010, p. 221).

Seguindo raciocínio análogo, Passos et al. (2006, p. 195) complementam que a formaçáo do professor é um processo contínuo, tratando-se de "um fenômeno que ocorre ao longo de toda a vida e que acontece de modo integrado às práticas sociais e às cotidianas escolares de cada um, ganhando intensidade $\mathrm{e}$ relevância em algumas delas". Assim, como exemplo de diferentes contextos que podem integrar o percurso de formação da trajetória de vida e profissional do professor, destacam-se os quatros momentos explicitados por Imbernón (2011): o primeiro trata da experiência discente, referindo-se às vivências que, enquanto alunos, os futuros professores tiveram na escola; o segundo é o da formação inicial, proporcionando uma preparação formal, sistemática e específica; o terceiro configura-se como o período de iniciação à profissáo docente; e o quarto é o da formação permanente, que se constitui a continuidade do desenvolvimento promovido por meio de diferentes contextos e instituiçôes.

Dessa forma, a opção pela formação inicial do professor como contexto para as consideraçóes e reflexóes deste artigo decorre do fato de que, por meio das licenciaturas, a instância desse tipo de formação se constitui no único espaço institucionalizado que tem por finalidade o desenvolvimento do profissional docente para atuar na educação básica. Em virtude disso, a formação inicial é caracterizada por um "momento formal em que processos de aprender a ensinar e aprender a ser professor começam a ser construídos de forma mais sistemática, fundamentada e contextualizada" (MIZUKAMI, 2008, p. 216) e também possibilita dotar esses profissionais "de uma bagagem sólida nos âmbitos científicos, cultural, contextual, psicopedagógico e pessoal que deve capacitar o futuro professor ou professora a assumir a tarefa educativa em toda sua complexidade" (IMBERNÓN, 2011, p. 68).

\section{Alguns desafios e demandas da formação inicial de professores}

A evidência mais clara dos novos desafios e demandas da contemporaneidade para a formação inicial de professores no Brasil refere-se à homologação, pelo Ministério da Educação, em 2015, das novas DCN para a formação inicial em nível superior (cursos de licenciatura, de formação pedagógica para graduados e de segunda licenciatura), por meio da Resolução no 2/CNE/2015, que, dentre 
outros aspectos, explicita no primeiro parágrafo do Art. $2^{\circ}$ a compreensão que se tem a respeito da docência:

Como ação educativa e como processo pedagógico intencional e metódico, envolvendo conhecimentos específicos, interdisciplinares e pedagógicos, conceitos, princípios e objetivos da formação que se desenvolvem na construção e apropriação dos valores éticos, linguísticos, estéticos e políticos do conhecimento inerentes à sólida formação científica e cultural do ensinar/ aprender, à socialização e construção de conhecimentos e sua inovação, em diálogo constante entre diferentes visóes de mundo (BRASIL, 2015b).

Essa definição evidencia indícios de alguns dos conhecimentos, saberes e habilidades que devem compor a base do profissional docente (LEITE, 2016). A complexidade da formação desse profissional se amplia, especialmente, quando considerado o fato de que o processo de ensinar, bem como a ação educativa implícita no exercício da profissão do professor, não se restringe a um grupo homogêneo de estudantes organizados em um nível único de ensino, afinal, o professor é formado para atuar na educação básica em diferentes níveis, que possuem especificidades distintas. Além do mais, há de se considerar que, mesmo em turmas de uma mesma categorizaçáo, há alunos com diferentes experiências de vida e, portanto, com conhecimentos distintos e que devem ser considerados no processo de ensino-aprendizagem. Outras particularidades e especificidades ainda precisam ser valorizadas, como o fato de haver alunos com deficiências e que, portanto, necessitam também de um atendimento de acordo com suas demandas cognitivas e físicas.

Nesse sentido, é importante que, na formação do profissional docente, assegurem-se, conforme o Art. $5^{\circ}$ das DCN estabelecidas pela Resolução $n^{\circ}$ $2 / \mathrm{CNE} / 2015$, conhecimentos e práticas que conduzam "à aprendizagem e ao desenvolvimento de todos(as) os(as) estudantes durante o percurso educacional por meio de currículo e atualização da prática docente que favoreçam a formação e estimulem o aprimoramento pedagógico das instituições" (BRASIL, 2015b). Esses aspectos devem ser instituídos na formação inicial do professor, conforme estabelece o Art. $3^{\circ}$, parágrafo quinto, das mesmas DCN, que, dentre outros, considera como princípio da formação de profissionais do magistério (formadores e estudantes) da educaçáo básica um:

compromisso com projeto social, político e ético que contribua para a consolidação de uma nação soberana, democrática, justa, inclusiva e que promova a emancipação dos indivíduos e grupos sociais, atenta ao reconhecimento e à valorização da diversidade e, portanto, contrária a toda forma de discriminaçáo (BRASIL, 2015b). 
Nessa conjuntura, essas DCN se configuram como fruto e, ao mesmo tempo, definidoras dos desafios e demandas para a formação inicial de professores, visto que retomam problemas e dilemas antigos dos cursos de licenciatura e também possibilitam outras discussôes e debates acerca do cenário educacional brasileiro, especialmente, sobre a formação docente. Entre os muitos fatores abordados, estão aqueles que têm sido apontados como causas do desacerto entre os saberes desenvolvidos, construídos ou adquiridos pelo professorado durante os cursos de formação inicial e aqueles exigidos no decorrer do exercício da profissão docente, como, por exemplo: a separação entre as disciplinas de conteúdo específico e as pedagógicas; a dicotomia entre teoria e prática e a desarticulação entre formação acadêmica e a realidade escolar (LEITE, 2016).

Além desses, vale destacar que há alguns fatores que fazem parte da história da formação inicial de professores e que a desafiam a superá-los ou amenizá-los em nome da melhoria da formação docente e da educação básica: a desarticulação entre a proposta pedagógica e a organização institucional dos cursos de licenciatura; o isolamento das instituiçóes formadoras diante das novas dinâmicas culturais e demandas sociais apresentadas à educação escolar; o distanciamento entre a formação docente e os sistemas de ensino da educação básica; a desconsideração do repertório de conhecimentos dos docentes em formação; a falta de clareza sobre quais são os conteúdos que o futuro professor deve aprender e a restrição da atuação do futuro professor à regência em sala de aula, sem considerar as demais dimensões da sua atuação profissional.

Isso caracteriza, dentre outros aspectos, a necessidade da superaçáo de um currículo fragmentado e sua substituição por um que seja integrado, capaz de favorecer práticas pedagógicas envolvendo as diferentes áreas e sem desconsiderar as particularidades de cada uma delas. Assim, é necessário que a formação de professores não seja pensada "a partir das ciências e seus diversos campos disciplinares, como adendo destas áreas, mas a partir da função social própria à escolarização - ensinar às novas geraçóes o conhecimento acumulado e consolidar valores e práticas coerentes com nossa vida civil" (GATTI; BARRETO, 2009, p. 257).

Dessa forma, percebe-se a urgente necessidade de se promover, na formação inicial de professores, de forma equilibrada, tanto o domínio de conteúdos das respectivas áreas de referência - tradicionalmente conhecidas como "disciplinas" - , quanto o domínio de conhecimentos próprios da profissão docente, balizados por princípios e valores que extrapolam o restrito espaço escolar. Nesse sentido, observa-se no Art. $7^{\circ}$ das DCN estabelecidas na Resolução no 2/CNE/2015, que, dentre as especificidades das demandas formativas necessárias à atividade docente, indica-se a de se "dominar os conteúdos específicos e pedagógicos e as abordagens teórico metodológicas do seu ensino, de forma interdisciplinar e adequada às diferentes fases do desenvolvimento humano" (BRASIL, 2015b), assim 
como também se evidencia a necessidade de garantir que, pela formação inicial, o futuro professor seja capaz de "relacionar a linguagem dos meios de comunicação à educação, nos processos didático-pedagógicos, demonstrando domínio das tecnologias de informação e comunicação para o desenvolvimento da aprendizagem" (BRASIL, 2015b).

Assim, destaca-se também outra demanda recorrente, uma vez que o advento do uso das tecnologias de informação e comunicação (TIC) e suas aplicações na educação básica submetem a formação inicial de professores ao dever de qualificar os futuros docentes quanto ao domínio dessas tecnologias para o desenvolvimento da aprendizagem dos alunos e para a inserção da escola na sociedade tecnológica.

Tal aspecto já constava das DCN de 2001 (Parecer no 9/CP/CNE/2001), que apontavam que se o uso de novas TIC estava sendo colocado como um importante recurso para a educaçáo básica deveria valer também para a formação de professores e, assim, defendiam que os cursos de formação docente deveriam garantir, com qualidade e quantidade suficientes, recursos de TIC para que formadores e futuros professores realizassem satisfatoriamente as tarefas de formação (BRASIL, 2001a).

Entre os desafios e demandas elucidados até aqui, sobressaltam-se aqueles que são recorrentes e que emergem na e da contemporaneidade, consequentes, conforme Gatti e Barreto (2009, p. 12), das "urgências colocadas pelas transformaçóes sociais que atingem os diversos âmbitos da atividade humana e penetram os muros da escola", implicando a necessidade de se buscar "concepçóes e práticas educativas que possam contribuir significativamente para a construção de uma sociedade mais justa, democrática e moderna”. No movimento desses desafios e demandas à formação inicial de professores, destacamse as especificidades próprias das diferentes etapas e modalidades de ensino da educação básica.

\section{Desafios e demandas da formação de professores relativos às especificidades da educação básica}

No tocante às diferentes etapas da educação básica (educação infantil, ensino fundamental e ensino médio), é requerida formação específica e adequação das competências e habilidades para os futuros professores, no atendimento às DCN, para cada uma dessas etapas, considerando-se a garantia do domínio dos conhecimentos previstos para a conclusão da escolaridade básica. Além disso, a formação inicial de professores deve assegurar o conhecimento dos aspectos físicos, cognitivos, afetivos e emocionais do desenvolvimento humano das diferentes faixas etárias e dos distintos períodos da vida (infância, adolescência, juventude e 
vida adulta) que configuram o público discente da educação básica, já estando tais requisitos formativos previstos desde as DCN de 2001 (BRASIL, 2001a, p. 46), para que,

[...] independentemente da etapa da escolaridade em que o futuro professor vai atuar, ele tenha uma visão global sobre esta temática, aprofundando seus conhecimentos sobre as especificidades da faixa etária e das práticas dos diferentes grupos sociais com a qual vai trabalhar.

Considerando os desafios e demandas para a formaçáo inicial de professores, no que diz respeito às modalidades de ensino da educação básica (educação de jovens e adultos, educação especial, educação profissional e tecnológica, educação do campo, educação escolar indígena, educação a distância e educação escolar quilombola), eis que cada uma delas adquire contornos próprios, em conformidade com as suas especificidades, colocando em debate as dificuldades e dilemas da formação inicial, de modo que consigam atender e fomentar as exigências formativas para que os futuros docentes consigam desempenhar sua tarefa educativa nessas distintas modalidades, cada qual com uma legislação específica, consolidada, em parte, por meio das DCN da educação básica (BRASIL, 2013).

Tais desafios e demandas adquirem respaldo em função das peculiaridades e especificidades de cada uma dessas modalidades de ensino, que tornam impreterível a constituição de modelos pedagógicos próprios e diferenciados no atendimento às características singulares dos alunos inseridos nessas modalidades e, consequentemente, requerem uma formaçáo inicial de professores que seja específica para a atuaçáo em cada uma delas.

Esse seria o caso, a título de exemplo, da formação inicial de professores para a educação de jovens e adultos (EJA), que está claramente versada em suas DCN (Parecer no 11/CEB/CNE/2000), que recomendam que o "preparo de um docente voltado para a EJA deve incluir, além das exigências formativas para todo e qualquer professor, aquelas relativas à complexidade diferencial desta modalidade de ensino" (BRASIL, 2000, p. 56) e que "as licenciaturas e outras habilitaçóes ligadas aos profissionais do ensino não podem deixar de considerar, em seus cursos, a realidade da EJA" (BRASIL, 2000, p. 58). Ou, conforme já pressupunham as DCN para a formação de professores da educação básica (Parecer no 09/CP/CNE/2001), que os cursos de formação inicial docente não deixem de lado a questáo da EJA, que ainda é uma necessidade social expressiva, e não deixem de pensar as especificidades de seus educandos e de superar a prática de trabalhar com eles da mesma forma com que se trabalha com as crianças e adolescentes da educação básica.

Do mesmo modo, também a título de exemplo sobre a necessidade de formaçáo inicial de professores para o atendimento às especificidades das moda- 
lidades de ensino, destaca-se a previsão, nas DCN estabelecidas pela Resolução no 2/CNE/2015 (BRASIL, 2015b), da necessidade de diretrizes específicas para a formação inicial em nível superior e para a formação continuada voltada para as modalidades da educação escolar indígena, educação escolar do campo e educação escolar quilombola. Tais demandas vinculam-se, em sua origem, ao reconhecimento da necessidade de que o professor esteja preparado para valorizar e considerar a diversidade cultural nos processos educativos.

Dessa forma, entre as novas demandas por formação de professores na contemporaneidade, encontram-se aquelas originadas pelo processo de universalização da educação escolar ocorrido nas últimas décadas. A massificação da escola proporcionou novos contextos educativos, com diferentes perfis de alunos, requerendo, assim, uma reformulação dos próprios processos educativos e práticas escolares. Nesse processo, a escola fez-se presente em novos contextos culturais e passou a ter que enfrentar o desafio de reconhecer os valores da diversidade e da diferença dos distintos contextos como intrinsicamente inerentes à educação escolar.

Como resposta a essas demandas decorrentes da universalização da educação escolar, novos marcos legais se constituíram, regulamentando e indicando diretrizes para a formação inicial de professores. Especificamente no Brasil, a Constituiçâo de 1988 marca o início de um período com expressivos desdobramentos em forma de leis, diretrizes e resoluçóes relativas à formação inicial de professores, com vistas a se garantir o direito à educação específica e diferenciada e à promoção da diversidade cultural de diferentes contextos em que a escola passa a se inserir (BRASIL, 1988). Nesse sentido, a Lei no 9.394/96 organiza a educaçáo básica em modalidades, garantindo que as especificidades de cada contexto sejam levadas em consideraçáo pela escola, incluindo-se, entre outros, o perfil socioeconômico dos estudantes, o direito ao ensino bilíngue e a valorização das particularidades da história e das manifestaçōes culturais regionais (BRASIL, 1996).

Para configurar a formação inicial de professores, com vistas a se atender toda a complexidade que esses novos marcos legais pós-Constituição de 1988 estabeleceram no país, não foi suficiente a existência de uma única normativa do CNE para todas as licenciaturas. Sendo assim, resoluçóes específicas do CNE foram formuladas, a exemplo da de $n^{\circ} 01 / 2015 / C N E$ (BRASIL, 2015a), que estabeleceu diretrizes específicas para a formação de professores indígenas, sendo esse um exemplo de desafio contemporâneo da formação inicial de docentes no Brasil.

O reconhecimento legal de que o Brasil é um país multicultural e multiétnico, devendo seus sistemas de ensino valorizar e promover as diferenças e diversidades culturais existentes no território nacional, tem na formação inicial de professores indígenas um exemplo de políticas públicas específicas, que despontaram como necessárias tanto para se garantir os direitos individuais dos cidadãos com identidades culturais específicas quanto como medida de promoção dos direitos sociais coletivos de povos e sociedades distintas que compóem a nação brasileira. 
Como modalidade de ensino específica, a educação escolar indígena (EEI), no Brasil, surgiu com a Constituição de 1988 e com a Lei no 9.394/96. Contudo, a história da educaçáo escolar entre os povos indígenas no país se iniciou com o próprio processo de colonização, por meio da ação de missionários religiosos dos séculos XVI a XIX. Somente no fim do século XX é que novas políticas públicas de educação escolar demandaram a reorientação dos princípios e fins da escola na aldeia, incluindo-se diretrizes específicas para a formação inicial de professores. Assim, conforme Ferreira (2001), Freire (2004) e Vieira (2006), se inicialmente a educação escolar contribuiu para a assimilação e a integração forçada de povos indígenas à civilizaçáo ocidental, na contemporaneidade, novos marcos teóricos e legais voltam-se para a necessidade de manutenção da integridade física e cultural de cada povo indígena. Para tanto, a formação específica de professores para as escolas nas aldeias torna-se imprescindível.

Não obstante o reconhecimento legal das particularidades da EEI ter ocorrido no final dos anos 1980, somente após uma década foi efetivamente criada a categoria "professor indígena", por meio da Lei no 10.172, de 9 de janeiro de 2001, que instituiu o Plano Nacional de Educação para o período de 2001 a 2010 (BRASIL, 2001b). Dessa forma, partindo-se do pressuposto de que existe uma vinculação entre conhecimentos específicos e identidade cultural, a formação de professores indígenas, como desafio contemporâneo, busca responder à demanda das atuais políticas públicas que visam à manutenção e à reprodução das culturas locais e das identidades culturais dos diferentes povos que compóem o território brasileiro.

Observa-se que, diante do contexto multicultural e pluriétnico do Brasil, que determina múltiplos desafios a serem vencidos na formação inicial de professores no país, os marcos legais (leis e resoluçóes) estão pautados por avanços e conquistas sociais de diferentes segmentos que compóem a sociedade nacional, havendo, todavia, um retardamento entre a prescrição normativa e a consequente adequação dos processos de formação de professores, que está em andamento em diferentes instituiçóes formadoras. Isso ocorre, parcialmente, em razão da atualização recente das DCN. Resulta daí a necessidade de maior debate e análise dos desafios que as novas diretrizes determinam aos cursos de formação inicial de professores no Brasil.

\section{O papel das instituições formadoras para a superação dos desafios da formação contemporânea de professores}

Embora haja vários outros fatores externos à formação inicial que interferem no processo formativo do professor, é fundamental que as instituiçóes formadoras busquem, de forma mais efetiva, superar alguns dos desafios e demandas que são históricos e, portanto, recorrentes. Tal superação não se limita a apenas 
modificar a organização curricular de projetos de cursos de graduação, mas deve garantir que as mudanças indicadas nos projetos se constituam em práticas efetivas pelos diferentes professores formadores, de diferentes componentes curriculares. Parece ser esse um aspecto problematizado há algum tempo. Por exemplo, Gatti (1992, p. 70) já indicava "uma certa inércia das universidades quanto a repensar as licenciaturas". Para Lüdke (1994, p. 6), isso poderia estar relacionado ao fato de que, historicamente, "dentro do modelo que inspira a universidade brasileira, a formação de professores ocupa um lugar bastante secundário".

Além desses aspectos, as instituiçóes formadoras devem buscar enfrentar outros fatores externos aos cursos de licenciatura, como a mudança do perfil dos estudantes, a atratividade da carreira docente, o desprestígio da profissão de professor, as novas responsabilidades sociais atribuídas ao trabalho pedagógico e a baixa remuneração salarial, dentre outros (PEREIRA, 2006; GATTI, BARRETO, 2009), que, mesmo não sendo tratados explicitamente nas DCN de 2015 para a formação inicial em nível superior e para a formação continuada, são reconhecidamente relevantes por exercerem grande influência no processo formativo do docente e, consequentemente, constituem desafios para a formação inicial desses profissionais.

Nesse caso, tem-se uma dicotomia instaurada em relação à formação inicial de professores: se, por um lado, chama a atençâo o lugar secundário que a formação inicial de docentes ocupa no modelo universitário brasileiro (LÜDKE, 1994; GATTI; BARRETO, 2009), por outro, fica evidenciada a sua importância e, conforme enfatizam Gatti e Barreto (2009, p. 11-12):

De qualquer ângulo que se focalize a questão, quer na perspectiva dos que se nutrem dos ideais de educação para a construção de uma sociedade justa na distribuição de seus bens e na preservação de valores de solidariedade e de coesáo social, quer na perspectiva dos que se preocupam com a eficiência interna dos processos educativos e com a eficácia na preparação do aluno para participar das transformaçóes em curso no mundo contemporâneo, a formação de professores sobressai como fator relevante.

Por fim, são plenamente justificáveis e compreensíveis, diante dos desafios e dilemas colocados para a formaçáo inicial de professores na contemporaneidade, as mudanças propostas pelas DCN de 2015 para a formação inicial em nível superior e para a formação continuada, com as consequentes açóes demandadas às instituiçóes formadoras, destacando-se entre elas, como as mais visíveis: a ampliaçáo da carga horária dos cursos de licenciatura, passando-se ao mínimo de 3.200 horas, diante das 2.800 horas anteriores, com duração mínima de 4 anos, e o prazo, até junho de 2017 (posteriormente prorrogado para julho de 2018), para que os projetos dos cursos de licenciatura estejam devidamente adequados a essas novas DCN. 


\section{Considerações finais}

Pelo exposto neste artigo, foi possível conhecer algumas demandas da formação inicial de professores na contemporaneidade, que se constituem em desafios para as instituiçóes promotoras de cursos de formação de professores. Cabe destacar que os aspectos elucidados no texto não trataram especificamente da formaçáo de professores de uma determinada área de conhecimento. Referiram-se, de forma geral, à formação de professores para atuarem na educação básica.

Destaque-se, ainda, que, embora as discussões tecidas no artigo tenham tomado como base as DCN estabelecidas na Resolução no 2/CNE/2015, sabe-se que a formação de professores no Brasil poderá ganhar novos contornos e, consequentemente, enfrentar novos desafios, a partir de tentativas de mudanças em andamento nas políticas oficiais de formação inicial e de configuração da educação básica, com destaque para a reformulação do ensino médio, a Base $\mathrm{Na}$ cional Comum Curricular e a proposta de Residência Pedagógica. Uma análise do mérito dessas mudanças em andamento fugiria ao escopo deste artigo, mas é relevante para a projeção de possíveis demandas e desafios futuros à formação docente no país.

Não obstante o volume de pesquisas e discussões produzidas sobre a formação docente no Brasil nos últimos anos, verifica-se ainda que grande parte dos desafios relacionados a essa questão no país não foi superada no contexto formativo, conforme amplamente apontado na construção das DCN de 2015: distanciamento entre o ensino na formação inicial e as necessidades da profissão docente; falta de articulação entre teoria e prática, bem como entre componentes curriculares de cunho específico e pedagógico; proximidade, por meio de parcerias, entre as IES e a escola; isolamento das instituiçóes formadoras diante das novas dinâmicas culturais e demandas sociais apresentadas à educação escolar; a não abordagem de conhecimentos voltados para o uso das TIC na formação inicial e a falta de uma construção de repertório de conhecimentos, saberes e habilidades que valorize e considere a diversidade cultural em suas diferentes dimensóes, bem como oportunize, ao futuro professor, trabalhar em diferentes níveis de ensino da educação básica.

Ressalta-se, finalmente, que a configuração e o estabelecimento dos desafios à formaçáo inicial de professores, abordados ao longo deste artigo e definidos em regulamentos que se revestem da forma de leis e resoluçóes do CNE, são medidas necessárias, mas não suficientes para efetivas mudanças institucionais nos atuais processos de formação de professores no país.

A atualização de práticas formativas tradicionalmente existentes, tendo como objetivo a superação de atuais desafios postos à formação inicial de professores, demandará um aprofundamento do debate nos espaços acadêmicos, bem 
como decisóes políticas que passam, necessariamente, por profundas reformulações nos cursos de licenciatura existentes, a partir de uma maior organicidade entre o Plano de Desenvolvimento Institucional (PDI), o Projeto Pedagógico Institucional (PPI) e o Projeto Pedagógico de Curso (PPC).

Há desafios específicos que as instituiçóes brasileiras enfrentam, nesse aspecto, em razão de constantes mudanças de parâmetros, diretrizes, sistemas de avaliação e políticas nacionais da formação docente no país, o que dificulta, de certa forma, a consolidação de tipos e modelos de formação inicial de professores no Brasil.

Nesse sentido, apesar de recentes, as DCN de 2015, ainda em implementação e tendo incorporado algumas das discussóes tratadas em diretrizes específicas anteriores, possivelmente passarão novamente por atualizaçôes, em razão da reconfiguração curricular que está sendo imposta à educação básica. Assim, a consolidação de políticas públicas de formação inicial de professores no país, para um período mais longo do que a história recente tem registrado, configura-se como um último desafio a ser apontado e que demandará esforços institucionais e políticos para além do teor prescritivo dos marcos legais de formação de professores no Brasil.

\section{Referências}

BRASIL. Ministério da Educação. Conselho Nacional de Educação. Câmara de Educação Básica. Parecer $n^{\circ}$ 11/CEB/CNE/2000. Dispóe sobre as Diretrizes Curriculares Nacionais para a Educação de Jovens e Adultos. Brasília: CEB/CNE/MEC, 2000.

Ministério da Educação. Conselho Nacional de Educação. Conselho Pleno. Parecer no 09/CP/CNE/2001. Dispóe sobre as Diretrizes Curriculares Nacionais para a Formação de Professores da Educação Básica, em nível superior, curso de licenciatura, de graduação plena. Brasília: CP/CNE/MEC, 2001a.

. Ministério da Educação. Conselho Nacional de Educação. Conselho Pleno. Resolução no 01/CP/CNE/2015. Institui Diretrizes Curriculares Nacionais para a Formaçáo de Professores Indígenas em cursos de Educação Superior e de Ensino Médio e dá outras providências. Brasília: CP/CNE/MEC, 2015a.

Ministério da Educação. Conselho Nacional de Educação. Conselho Pleno. Resolução $n^{o}$ 02/CP/CNE/2015. Define as Diretrizes Curriculares Nacionais para a formação inicial em nível superior (cursos de licenciatura, cursos de formação pedagógica para graduados e cursos de segunda licenciatura) e para a formação continuada. Brasília: $\mathrm{CP} / \mathrm{CNE} / \mathrm{MEC}, 2015 \mathrm{~b}$.

Ministério da Educação. Secretaria de Educação Básica. Secretaria de Educação Continuada, Alfabetização, Diversidade e Inclusão. Secretaria de Educação Profissional e Tecnológica. Conselho Nacional da Educação. Câmara Nacional de Educação Básica. Diretrizes Curriculares Nacionais Gerais da Educação Básica. Brasília: DICEI/SEB/MEC, 2013. 
BRASIL. Presidência da República. Casa Civil. Subchefia para Assuntos Jurídicos. Constituição da República Federativa do Brasil de 1988. Brasília: Presidência da República, 1988.

Presidência da República. Casa Civil. Subchefia para Assuntos Jurídicos. Lei $n^{o}$ 9.394, de 20 de dezembro de 1996. Estabelece as diretrizes e bases da educação nacional. Brasília: Presidência da República, 1996.

Presidência da República. Casa Civil. Subchefia para Assuntos Jurídicos. Lei $n^{o}$ 10.172, de 9 de janeiro de 2001. Aprova o Plano Nacional de Educaçáo e dá outras providências. Brasília: Presidência da República, $2001 \mathrm{~b}$.

FERREIRA, M.K.L. A Educação Escolar Indígena: Um diagnóstico crítico da situação no Brasil. In: SILVA, A.L.; FERREIRA, M.K.L. (Orgs.). Antropologia, História e Educação: A Questão Indígena e a Educação. São Paulo: Global, 2001.

FREIRE, J.R.B. Trajetória de muitas perdas e poucos ganhos. In: Educação escolar indígena em Terra Brasilis: Tempo de novo descobrimento. Rio de Janeiro: IBASE, 2004.

GATTI, B.A. A formação dos docentes: o conforto necessário - professor $\times$ academia. Cadernos de Pesquisa, Sáo Paulo, n. 81, p. 70-74, maio 1992.

GATTI, B.A.; BARRETO, E.S.S. (Orgs.). Professores do Brasil: impasses e desafios. Brasília: UNESCO, 2009.

IMBERNÓN, F. Formação Docente e Profissional: formar-se para a mudança e a incerteza. 9. ed. São Paulo: Cortez, 2011.

Formação permanente do professorado: novas tendências. Tradução de Sandra Trabucco Valenzuela. São Paulo: Cortez, 2009.

LEITE, E.A.P. Formação inicial e base de conhecimento para o ensino de matemática na perspectiva de professores iniciantes da educação básica. 269f. Tese (Doutorado em Educação) - Programa de Pós-Graduação em Educação, Universidade Federal de São Carlos, São Carlos, 2016.

LIMA, S.M.; REALI, A.M.M.R. O papel da formação básica na aprendizagem profissional da docência (aprende-se a ensinar no curso de formação básica?). In: REALI, A.M.M.R; MIZUKAMI, M.G.N. (Eds.). Formação de professores, práticas pedagógicas e escola. São Carlos: EdUFSCar, 2010.

LÜDKE, M. Formação de docentes para o ensino fundamental e médio: as licenciaturas. Rio de Janeiro: CRUB, 1994.

MIZUKAMI, M.G.N. Aprendizagem da docência: conhecimento específico, contextos e práticas pedagógicas. In: NACARATO, A.M. A formação do professor que ensina matemática perspectivas e pesquisas. Belo Horizonte: Autêntica, 2008. p. 213-231.

PASSOS, C.L.B.; NACARATO, A.M.; FIORENTINI, D.; MISKULIN, R.G.S.; GRANDO, R.C.; GAMA, R.P.; MEGID, M.A.B.A.; FREITAS, M.T.M.; MELO, M.V. de. Desenvolvimento profissional do professor que ensina matemática: uma meta-análise de estudos brasileiros. Revista Quadrante, v. XV, n. 1-2, p. 193-219, 2006. Disponível em: shttp://www.apm.pt/files/ 09 lq 47fe12e32858f.pdf $>$. Acesso em: set. 2015. 
PEREIRA, J.E.D. Formação de professores: pesquisas, representações e poder. 2. ed. Belo Horizonte: Autêntica, 2006.

PIMENTA, S.G.; LIMA, M.S.L. Estágio e docência. 7. ed. São Paulo: Cortez, 2012.

SERRAZINA, M.L.M. Conhecimento matemático para ensinar: papel da planificação e da reflexão na formação de professores. Revista Eletrônica de Educação, v. 6, n. 1, maio 2012. http://dx.doi.org/10.14244/19827199355

VIEIRA, I.F. Educação escolar indígena: as vozes guarani sobre a escola na aldeia. Dissertação (Mestrado em Educação) - Universidade Federal de Santa Catarina, Florianópolis, 2006.

Recebido em 27 de julho de 2017.

Aceito em 02 de maio de 2018. 